\title{
Potential economic effects of TTIP for the Netherlands and the EU
}

Hugo Rojas-Romagosa 



\title{
Potential economic effects of TTIP for the Netherlands and the EU
}

\author{
Hugo Rojas-Romagosa* \\ CPB Netherlands Bureau for Economic Policy Analysis
}

June 2016

\begin{abstract}
The Transatlantic Trade and Investment Partnership (TTIP) is a comprehensive preferential trade agreement that is expected to have a significant effect in EU and US bilateral trade and investment relations. Negotiations are ongoing, so we use a scenario analysis to estimate the potential effects of TTIP under likely negotiated outcomes. In our main scenario, we assume a final trade deal where current tariffs are eliminated and non-tariff barriers are significantly reduced. Using a CGE model (WorldScan) we simulate the potential economic effects for the Netherlands. We find that US-Dutch bilateral trade doubles and this is translated into a positive but moderate effect on income of $1.7 \%$ for the Netherlands by the year 2030. These potential gains are higher than those for the EU and the US (both around 1\%).
\end{abstract}

Keywords: TTIP, preferential trade agreements, CGE models JEL Classification: F13, F17, C68

\section{Introduction}

The Transatlantic Trade and Investment Partnership (TTIP) is currently being negotiated between the European Union (EU) and the United States (US). This deep integration agreement consists of three main pillars: eliminating tariffs, regulatory cooperation to reduce non-tariff barriers (NTBs) ${ }_{1}^{1}$, and other behind the border rules. Of these, the first two components will have direct economic impacts, and it is expected that the NTB reductions related to TTIP will yield the most economic impact (Francois et al., 2013, Egger et al., 2015).

${ }^{*}$ I would like to thank Joseph Francois and Miriam Manchin for providing me with the STATA code for the NTB estimations; Albert van der Horst, Clemens Kool and Gerdien Meijerink for valuable comments, and Emelie Walraven for research assistance.

${ }^{1}$ NTBs are also referred to as non-tariff measures (NTMs) and/or technical barriers to trade (TBTs). 
Since the EU and the US economies account for roughly half of world output and world trade, the scope and international impact of TTIP is considerable. The relatively large integration of both blocs has been the result of the post-war trade liberalisation process, which also included a significant increase in transatlantic investments - both blocs are also each other's most important investment partners ${ }^{2}$ This trade liberalisation process, however, has been mostly driven by the reduction of tariff rates. With relatively low tariffs levels at present, the economic focus of TTIP has shifted to the reduction of the biggest remaining hurdles in transatlantic trade: non-tariff barriers (NTBs). Thus, a comprehensive agreement that includes NTBs is expected to provide the most economic impact.

Much of the general debate on TTIP, however, has focused on the desirability of regulatory convergence and other political topics. Although these issues are central to the negotiations on TTIP, and the political aftermath of the negotiations, in this paper we focus our analysis exclusively on the economic perspective 3

The main objective of this paper, therefore, is to analyse the potential economic effects of TTIP for the Netherlands. To achieve this goal we start by a short description of the main economic elements being negotiated under TTIP and their potential economic effects. We then summarise the main studies that have estimated the economic effects of TTIP. However, these previous TTIP studies have focused on the overall gains for the EU and some of the larger EU countries ${ }^{4}$ Therefore, in this study we use WorldScan -the CPB in-house computational general equilibrium (CGE) model- to assess the potential economic effects of TTIP for the Netherlands. As part of the TTIP simulations, we have two main policy shocks: elimination of tariffs between the US and all EU countries and reduction in NTB costs. For the second shock, we follow the recent methodological approach in Egger et al. (2015) to estimate the expected NTB reductions associated from TTIP. In our "full" TTIP simulation we combine the previous two policy shocks to have both the tariff elimination and the NTB cost reductions.

We find macroeconomic effects for the US and for the aggregated EU region that are similar to previous CGE studies (Francois et al., 2013; Egger et al., 2015). For the Netherlands, we find that GDP and consumption per capita increase by the year 2030 by more than the EU average, by $1.7 \%$ and $3.1 \%$ respectively. This GDP increase is driven by a strong surge of bilateral trade between the US and the EU, which is expected to double: EU exports to the US increase by $111 \%$, while US exports to the EU raise by $119 \%$. Dutch exports to the US increase by $95 \%$, but total exports (to all destinations) increase by a more moderate $4 \%$. TTIP also creates, therefore, strong trade diversion patterns and Dutch exports to other EU countries

\footnotetext{
${ }^{2}$ When each individual EU country is analysed separately, however, intra-EU trade represents the majority of EU countries' trade flows. For the Netherlands, intra-EU trade represents around $70 \%$ of total trade and US trade is around $7 \%$.

${ }^{3}$ See Ecorys (2016) for the potential environmental and social effects of TTIP.

${ }^{4}$ Studies that analysed the specific results for The Netherlands are Ecorys $(2012,2016)$. These studies are based on the same CGE modelling as in Francois et al. (2013) and another methodology to estimate NTB reductions associated with TTIP, which yields NTB information for a limited number of sectors (cf. Berden and Francois, 2015).
} 
decreases by $2 \%$ and to third regions by roughly $3 \%$. These trade diversion effects also result in a relatively small decrease in trade and GDP for non-TTIP regions.

With respect to the labour market, our simulations show that with a full TTIP scenario that eliminates tariffs and reduces NTBs, Dutch average wages will increase by more than $2 \%$. More importantly, the wages of both low- and high-skill workers are expected to rise. This implies that TTIP will not significantly affect wage nor income inequality. The sectoral reorganisation of production, however, implies that workers in declining sectors will need to relocate to other sectors. This labour displacement will have short term adjustment costs for those workers that need to change employment. However, these additional costs are relatively small, since only a small proportion of workers would have to change jobs and move from one sector to another, in comparison to the job creation and destruction that occurs on a yearly basis. In particular, we expect that about 1.5\% of total jobs (around 114,000 jobs) will be reallocated to other sectors in a 13 year period, while on a yearly basis, $13 \%$ of total jobs (around one million jobs) are either created or destroyed in the Netherlands (Brull et al., 2010).$^{5}$

Finally, it is important to mention that these potential effects are likely to underestimate the full economic effects of TTIP, since our methodology does not analyse additional economic effects of TTIP related to public procurement provisions, increased FDI and dynamic effects from trade.

This paper proceeds as follows. We first explain in Section 2 the main characteristics of TTIP and we list the potential economic effects. In Section 3 we summarise the main results of the economic studies that have analysed TTIP. We then explain in Section 4 the WorldScan CGE model, how the TTIP experiment is modelled and what are the main economic results for the Netherlands. In Section 5 we discuss some additional economic effects related to TTIP and we conclude in Section 6 .

\section{TTIP and its potential economic outcomes}

\subsection{What is TTIP?}

The setup of TTIP is to become a deep and comprehensive preferential trade agreement (PTA) between the European Union and the United States of America. As such, TTIP is part of a broader trend of mega-regional arrangements and a number of other "deep integration" PTAs that go beyond tariff reductions and are characterised by behind-the-border measures and new rules for important trade-related issues 6 Recent "deep" PTAs include the Trans-Pacific Partnership (TPP), the freshly negotiated treaty between the EU-Canada (the Comprehensive Economic and Trade

\footnotetext{
${ }^{5}$ This is an indicator of job turnover, where both the newly created and the jobs that no longer exist (destroyed) are summed together and compared to the total number of jobs.

${ }^{6}$ These measures apply to a broad set of topics, such as increased cooperation and harmonisation of regulations, open services markets, technical and regulatory barriers to trade, investment and competition, access to public contracts and (i.e public procurement), and investor protection legislation, among others.
} 
Agreement, CETA) and the recently launched trade negotiations between the EU and Japan 7 By contrast, most "common" PTAs are focused on preferential market access by decreasing tariffs and streamlining customs rules.

The main economic features of the TTIP negotiations are usually grouped into three components (cf. Hamilton and Pelkmans, 2015). First, eliminating the remaining market access restrictions (i.e. tariffs and quotas). The current tariffs between the EU and the USA are already relatively low -at around $3 \%$ in averag $\AA^{8}$ so eliminating these remaining tariffs is expected to only increase trade slightly.

Second, regulatory cooperation that is expected to reduce NTB costs. This effect generates a direct trade cost reduction that has an unambiguous economic effect through increased bilateral trade flows. There is empirical evidence that the trade costs associated with NTBs are significantly more important than those associated with tariffs (cf. Ecorys, 2009). This component has received the most attention in the economic literature so far and we analyse the different aspects of regulatory cooperation in the following sections.

Finally, the third component groups other behind the border rules $9^{9}$ These other rules are primarily concerned with legal issues that do not have a direct economywide economic impact and as such, are not included in our main economic studies on TTIP 10

\section{$2.2 \quad$ Regulatory cooperation and NTBs}

\subsubsection{What is regulatory cooperation?}

In the current Transatlantic setting, different historical and institutional approaches to similar regulatory challenges have generated two distinct regulatory environments in the US and the EU. This development has had the unintended consequence of increasing costs for export firms, which have to comply with each region's regulations. These increased costs are what we refer to -in a generic way- as non-tariff barriers (NTBs).

The TTIP negotiations have pursued consultative mechanisms among regulatory agencies to achieve regulatory convergence and cooperation. This process should partially eliminate redundant regulations, identify more efficient procedures, and

\footnotetext{
${ }^{7}$ There are also differences in scope between these deep trade agreements. Some are more comprehensive or "broad" -including a larger number of topics, while others go "deeper" in the degree of integration. For example, TPP is a broad agreement, while CETA is both broad and has deeper integration provisions.

${ }^{8}$ Although still important for some specific sectors, such as agriculture, textiles and apparel, footwear and processed foods.

${ }^{9}$ Which include: competition rules, intellectual property rights (IPRs), investment protection, investor-state dispute settlements (ISDS) and Government-to-Government dispute settlements, among others.

${ }^{10}$ Negotiating priorities are: public procurement, rules of origin, rules for administered protection (e.g. anti-dumping and countervailing duties), intellectual property (including geographical indications), and financial regulations. For instance, see Poulsen et al. (2015) and Baetens (2015) for an in-depth analysis on ISDS issues.
} 
improve regulatory transparency (Chase and Pelkmans, 2015). The most important point, however, is that this regulatory cooperation procedure will be done while keeping intact the high levels of safety, health, environment, investor/saver, labour, and consumer protection already in existence in both the EU and US (Hamilton and Pelkmans, 2015). In general, protection levels are policy objectives that reflect fundamental societal preferences that are upheld by constitutional and legal constraints. For instance, the upholding of these protection levels is an explicit condition required by the European Parliament (July 8th 2015) for the future approval of TTIP. Thus, regulatory cooperation under TTIP will not change labour standards, environmental legislation, consumer protection rules, human health and safety, food safety standards, and other protection levels (see also SER, 2016).

To sum up, the aim of TTIP negotiations is to keep the existing EU- and USspecific protection levels intact, while the regulations and procedures that are used to ensure and evaluate these protection levels (i.e. the means to achieve current protection levels) are harmonised and/or mutually recognised. Given that there will not be any protection level convergence, then the scope of regulatory cooperation will be effectively bounded. This means that it will not be feasible to achieve a broad nor complete regulation harmonisation, and some of the existing regulatory divergences will remain. In the economic analysis below, this fact is reflected on the common assumption that only a fraction -usually $50 \%$ or less- of the non-tariff barriers costs currently associated with regulatory divergences could be removed as part of the TTIP agreement.11

\subsubsection{NTBs and trade effects of regulatory cooperation}

The process of regulatory cooperation within TTIP is expected to reduce NTB costs. In other words, the improved transparency and cooperation on regulations is expected to reduce cross-border trade barriers and additional costs between both blocs. In practice, however, there are a vast number of such regulations and procedures. In general, regulatory cooperation encompasses a very extensive range of different types of technical regulations, sector- and product-specific regulations, and the cooperation of several regulatory agencies ${ }^{12}$ For instance, harmonisation and/or recognition of technical requirements and procedures on product testing, inspection and certification, and labelling regulations, among others. Egan and Pelkmans (2015) explain why these regulations are central to TTIP negotiations and why they are also difficult to address directly. They also argue that regulatory equivalence (cross-recognition of procedures) is a more viable option in many cases than regulatory convergence (harmonisation).

Even though this process of regulatory cooperation is expected to be significant under TTIP, the actual possibilities to reduce costs associated with regulation is

\footnotetext{
${ }^{11}$ See Section 4.3 for further details.

${ }^{12}$ See Egan and Pelkmans (2015) for an in-depth analysis of domestic regulation in both the US and the EU, current international regulatory cooperation topics, and the possible channels of regulatory cooperation within TTIP.
} 
limited by legal and political constraints (Chase and Pelkmans, 2015). Unlike tariffs, many regulations (and their associated NTB costs) cannot simply be removed, as they often serve important and legitimate domestic objectives like product safety and environmental protection. Differences in the social and political approach to risk and consumer protection make even the obvious regulation a complex issue 13 As explained in Egger et al. (2015) NTBs are adopted for a wide variety of reasons - only some of which have anything to do with their effects on trade- and removing NTBs can simply not be possible because of existing legal and institutional structures. For example, reducing NTBs may require constitutional changes, unrealistic legislative changes, or unrealistic technical changes.14

Given the broad range of regulations it is an enormous task to directly evaluate the economic impact of individual regulations and procedures ${ }^{15}$ Moreover, it is technically difficult to obtain accurate estimations of current country- and sectorspecific NTB cost levels. ${ }^{16}$ Most economic studies, therefore, have devised indirect methods to estimate how regulatory cooperation can translate into specific NTB cost decreases. Berden and Francois (2015), in particular, review the most recent methods that have been employed to quantify NTBs within TTIP.

Even under the limitations expressed above and the mandate on TTIP negotiations - to yield regulatory convergence without lowering protection levels- the process of regulatory cooperation can still yield significant economic benefits. In many cases the potential costs associated with NTBs may still be mitigated or reduced through partial regulatory convergence and mutual recognition. While this is likely to be a difficult process, the potential benefits in terms of productivity and incomes are substantial (Berden and Francois, 2015). For example, the safety and consumer protection levels of the automobile industry in both regions are very similar, but divergent regulations require that European car manufacturers crash over a hundred custom-made models -in addition to those already crashed to meet the European regulations- to meet the different safety, testing, and certification requirements in the US. This procedure costs large firms hundreds of millions of euros, and makes it near impossible for smaller European firms to sell in the US market (Chase and Pelkmans, 2015). If regulatory cooperation under TTIP can partially reduce some of these costs - while keeping the safety and consumer protection levels intact- this will translate into lower NTB costs that would allow a larger variety of automobiles sold in both regions, besides improving competition and final consumer prices.

\footnotetext{
${ }^{13}$ For specific examples see the firm survey responses to regulation in the Ecorys (2009) annex material, "Annex VI Business survey results". This annex provides examples on an industry basis of sources of cost differences when the same firms operate in multiple regulatory regimes.

${ }^{14}$ See Egger et al. (2015) for more on the relation between NTB cost reduction and political economy issues. They also analyse three specific cases of relevance to TTIP: regulation of cultural goods, food safety regulation, and financial regulation.

${ }^{15}$ In addition, there are still no concrete negotiated issues to this date that can be thoroughly analysed. As explained above, negotiations are still on-going without an official end date.

${ }^{16}$ By their nature, NTBs are seldom directly observable -in contrast to tariffs, and as such must be estimated as ad-valorem equivalents (AVEs) that can be used in economic policy simulations and analysis.
} 
Most TTIP studies, therefore, assume that a partial reduction of NTB costs, which maintains the current levels of protection can be achieved. Moreover, these NTB cost reductions will still be significant enough to generate important economic gains from TTIP.

\subsection{What are the potential economic effects from TTIP?}

Traditional PTAs and trade policy experiments are mainly concerned with tariff reductions. In this context, the changes in relative prices associated with sectorspecific changes in tariffs will translate into changes in bilateral trade flows: it is expected that lower sectoral tariffs will increase sectoral trade. In turn, these changes in relative prices and bilateral sectoral trade flows will create general equilibrium effects: broader macroeconomic shifts in production, consumption, employment, and welfare. It is also expected that the changes in bilateral trade flows will affect third countries as well, as long as these initial effects are relatively large.

As mentioned above, the current average tariff level between the USA and EU is already relatively low, so no substantial economic effects are expected from eliminating bilateral tariffs. The main economic effects of deep preferential trade agreements, such as TTIP, are driven by the potential impact of reduced NTB cost levels (Berden and Francois, 2015, Egger et al., 2015). It is expected that NTB cost reductions, if significant, can also be translated into significant economic effects. Moreover, these NTB cost reductions will not only affect those sectors where the barriers are reduced, but as with tariff reductions they will also have a direct effect on trade and an indirect general equilibrium effect.

In general, both regions are already highly integrated, so no broad economywide changes are expected. The combination of tariff elimination and NTB cost reductions, however, can create positive but limited welfare gains. Although these economy-wide changes are expected to be relatively small, there are some significant shocks in particular sectors, affecting production and consumption in these sectors and requiring workers to shift to those sectors that will expand.

\section{Review of economic studies on TTIP}

There have been several studies that have analysed the economic effects of TTIP.17 The best known analysis is the CEPR study by Francois et al. (2013). This is the reference study by the European Commission and DG Trade (European Commission, 2013 ) and the study used by most commentators This is a CGE-based analysis that uses previously estimated NTB levels (Ecorys, 2009) to construct a series of

\footnotetext{
${ }^{17}$ In a companion document (Bekkers and Rojas-Romagosa, 2016), we present an in-depth analysis of the various studies that have evaluated the economic impact of TTIP. In this section we present a summary of this survey.

18 See for example, The Economist (2013), Rodrik (2015), Wolf (2015), and The Guardian (2015). The importance of this study is highlighted by the request of the European Parliament to conduct an independent evaluation, which was done by Pelkmans et al. (2014).
} 
TTIP scenarios that combine tariff elimination, NTB reductions and spillover effects to third countries. This study, as well as other CGE-based analyses, find positive but limited real income and welfare effects.

Even though CGE models are considered to be the state of the art approach in assessing TTIP (Pelkmans et al. 2014, Mustilli, 2015), a set of papers based on new quantitative trade models have also been used to estimate the economic effects of TTIP. Even though these new methodological approach enhances the available tools to analyse trade policy, this new crop of structural gravity (SG) models have not yet created an established "standard" in the methodology. As such, the intrinsic characteristics of these models can change drastically from study to study and this is reflected in a wide array of predicted economic impacts from TTIP. Nevertheless, two main issues can explain the main different outcomes between CGE and SG models: the estimation and assumed level of NTB cost reductions, and particular modelling features 19

We find that the hybrid study by Egger et al. (2015) provides the most up-todate, detailed and reliable results on the potential effects of TTIP. It provides a reliable combination of NTB level estimations using gravity equations and incorporates them into a standard CGE model. As with other studies, it finds a substantial increase in bilateral trade flows between the US and the EU of $80 \%$. In general, total trade for both regions is expected to increase at around 5\%. These increased bilateral and total trade flows generate positive real income gains of around 1 to $2 \%$ for the EU and the US, while third-countries remain broadly unaffected, with the exception of some particular countries that currently trade more intensively with the TTIP countries. The changes in trade flows, in addition, are associated with moderate inter-sectoral changes in production and employment. Labour displacement caused by TTIP will, however, be well within the range of current year-on-year labour market mobility.

\section{Using WorldScan to assess TTIP}

\subsection{What is WorldScan?}

WorldScan is a computational general equilibrium model for the world economy (Lejour et al., 2006). The CGE modelling framework allows for economy-wide analysis and is the standard tool for trade policy analysis. Given that the WorldScan model is similar to the standard GTAP-class CGE models, ${ }^{20}$ we are using the same modelling techniques to assess TTIP as in the CEPR study (Francois et al., 2013), the CEPII study (Fontagné et al., 2013), and the study by Egger et al. (2015).

The key features of a CGE framework include the model that describes economic activity and behaviour, the underlying database that accounts for initial equilibrium

\footnotetext{
${ }^{19}$ See Section 6 in Bekkers and Rojas-Romagosa (2016) for a detailed analysis.

${ }^{20}$ The main characteristics and references to the standard GTAP model can be found at: www.gtap.agecon.purdue.edu/models/current.asp, while Hertel (2013) and Rutherford and Paltsev (2000) provide a detailed discussion of the GTAP-class models.
} 
of the global economy (e.g. the GTAP database), as well as a set of parameters that drive responses of agents to any given perturbation to the initial equilibrium. By employing a balanced and internally consistent global database, in tandem with an economic model that describes economic activity for a variety of sectors and agents in the global economy, any change in exogenous variables can be assessed to understand the effects on endogenous variables in the model. For example, preferential trade agreements (PTAs) are usually assessed by imposing a trade policy shock (changing bilateral tariffs and NTBs) to a baseline scenario. The resulting counterfactual scenario is then compared with the baseline to obtain the potential economic effects of the PTA21

The particular WorldSan model employed in this paper uses the latest version of the GTAP database (version 9 with base-year 2011) and distinguishes 21 goods and services sectors (see Table 8 in the Appendix), and 33 countries and regions. All EU countries are modelled separately, except for Belgium and Luxembourg, the three Baltic States, and Croatia, Cyprus and Malta (see Table 9 in the Appendix).

\subsection{Trade cost reductions associated with TTIP}

In this section we calculate and estimate the different trade costs reductions that are expected to occur once the TTIP agreement is applied. These trade cost reduction values will then be used as the inputs into the CGE model to simulate the TTIP experiment.

\subsubsection{Tariffs}

The most straightforward trade cost change within TTIP is the elimination of the current remaining tariffs within the US and the EU. The tariff levels are taken directly from the GTAP database.

As shown in Table 1, the current tariffs levels between the US and the EU are relatively low at an average of around 3\%. Some sectors, however, present aboveaverage levels: e.g. processed foods and motor vehicles.

\subsubsection{Estimating NTBs in goods}

Translating the NTB reductions associated with the expected regulatory cooperation within TTIP is a technically difficult task (see Section 2.2.2 above). In general, obtaining accurate estimations of current country- and sector-specific NTB levels is a complicated process. Berden and Francois (2015) review the most recent methods that have been employed to quantify NTBs within TTIP.

In this study, we employ the NTB estimation methodology from Egger et al. (2015), although using a different sectoral aggregation. ${ }^{22}$ They estimate NTB cost

\footnotetext{
${ }^{21} \mathrm{~A}$ more detailed and technical explanation of the WorldScan CGE model is provided in Appendix A.1.

${ }^{22} \mathrm{We}$ consider that this is the best available top-down approach, and as such, it is does not require the time-consuming firm-level data from bottom-up methodologies.
} 
Table 1: Applied tariffs in transatlantic trade in goods, 2011

\begin{tabular}{lcrr}
\hline Sector & code & US tariffs & EU tariffs \\
Agriculture & AGR & $2.9 \%$ & $3.8 \%$ \\
Primary energy and mining & OMI & $0.3 \%$ & $0.1 \%$ \\
Energy & ENG & $1.4 \%$ & $1.3 \%$ \\
Processed foods & PFO & $3.7 \%$ & $12.3 \%$ \\
Low-tech manufacturing & LTM & $3.3 \%$ & $2.2 \%$ \\
Metals and minerals & MEM & $2.0 \%$ & $2.4 \%$ \\
Chemical, rubber and plastics & CRP & $1.4 \%$ & $2.5 \%$ \\
Motor vehicles and parts & MVH & $1.0 \%$ & $6.7 \%$ \\
Other transport equipment & OTN & $0.5 \%$ & $1.4 \%$ \\
Electronic equipment & ELE & $0.3 \%$ & $0.6 \%$ \\
Other machinery and equipment & OME & $1.0 \%$ & $1.4 \%$ \\
\hline \multicolumn{2}{c}{ Source: GTAP-9 database. }
\end{tabular}

reductions in manufacturing goods using as reference the impact of deep PTAs on trade. This is done using a gravity model of bilateral trade, where bilateral trade flows are a function of (exporter- and importer-) country-specific fixed effects, a set of bilateral non-policy variables (e.g. geographical, cultural, historical), and two policy variables: the log tariff margin and a PTA depth measure. The NTB effect of trade agreements corresponds to the joint impact of PTAs conditional on tariffs and the depth of PTAs. Hence, NTB effects of PTAs must be associated with and can be estimated as effects beyond tariff reductions (Egger and Larch, 2011).

We follow Egger et al. (2015) and use the same econometric estimations and the GTAP-9 database ${ }^{23}$ This implies that we estimate existing NTB levels by 2011, and partially reduce these NTBs with the TTIP simulations ${ }^{24}$ Even though we use the same estimation technique and data, our results are slightly different due to the different sectoral aggregation we use.25

Once the parameters from gravity equation are estimated (i.e. the trade elasticities with respect to the tariff margin and the FTA-depth variables) these coefficients need to be translated into trade costs estimates as an ad-valorem equivalent (AVE). These AVEs are necessary to shock the CGE model. We follow the same formula used in Egger et al. (2015) to obtain the AVEs of NTBs. The estimated values are shown in Table 2. From this table we observe that our overall (total manufacturing) NTB estimations are close to those from Egger et al. (2015), although we have somewhat a lower value. This also applies to those sectors that are comparable between both studies.

\footnotetext{
${ }^{23}$ For technical details on the precise two-stage econometric estimations see Section 3.2 in Egger et al. (2015).

${ }^{24}$ In particular, the TTIP shock is simulated for 2017 and this also implies that the estimated NTB levels for 2011 remain constant until that date.

${ }^{25}$ Also, there are some minor differences on how the GTAP data was processed.
} 
Table 2: Estimated transatlantic NTB costs in manufacturing, ad valorem equivalents

\begin{tabular}{lccc}
\hline Sector & code & Egger et al. 2015 & own estimates \\
Agriculture & AGR & 15.8 & 15.4 \\
Primary energy and mining & OMI & 16.1 & 16.1 \\
Energy & ENG & n.a. & 17.8 \\
Processed foods & PFO & 33.8 & 32.0 \\
Low-tech manufacturing & LTM & 3.6 & 5.4 \\
Metals and minerals & MEM & 16.7 & 10.2 \\
Chemical, rubber and plastics & CRP & 29.1 & 24.1 \\
Motor vehicles and parts & MVH & 19.3 & 17.1 \\
Other transport equipment & OTN & n.a. & 12.4 \\
Electronic equipment & ELE & 1.8 & 0.4 \\
Other machinery and equipment & OME & 6.2 & 5.8 \\
Total manufacturing & & 13.7 & 12.6 \\
\hline
\end{tabular}

Notes: We have a different sectoral aggregation than in Egger et al. 2015. The sectors with values for Egger et al. 2015 roughly correspond to our own sectoral definitions.

\subsubsection{NTBs in services}

To obtain AVE for NTBs in services, we also follow Egger et al. (2015) and use the market access restrictions in services taken directly from the World Bank's STRI database (Jafari and Tarr, 2015). The corresponding AVE values are presented in Table 3. Note that the estimated NTBs levels in services are different by region -i.e. NTBs to enter the US market have different values than those for entering the EU market. This is not the case in the estimated NTBs for manufacturing goods in Table 2, where the econometric technique employed does not allow to distinguish region-specific NTB levels.

Table 3: Estimated transatlantic NTB costs in services, ad valorem equivalents

\begin{tabular}{lccc}
\hline Sector & code & EU NTBs & US NTBs \\
Construction & CNS & 4.6 & 2.5 \\
Air transport & ATP & 25.0 & 11.0 \\
Water transport & WTP & 1.7 & 13.0 \\
Other transport & OTP & 29.7 & 0.0 \\
Communication & CMN & 1.1 & 3.5 \\
Finance & OFI & 1.5 & 17.0 \\
Insurance & ISR & 6.6 & 17.0 \\
Other commercial services & OCS & 35.4 & 42.0 \\
Recreational and other services & ROS & 4.4 & 2.5 \\
Government and public services & OSR & n.a. & n.a. \\
\hline
\end{tabular}

Sources: Egger et al. (2015) and Jafari and Tarr (2015). 


\subsection{TTIP simulations using WorldScan}

In this section we present the results of our TTIP simulations using using our WorldScan model. We construct three scenarios using the information on trade cost reductions associated with TTIP:

1. Tariffs only (A): In our first scenario transatlantic tariffs are fully eliminated

2. NTBs only (B): In our second scenario NTBs for manufacturing and services are partially reduced. As in Egger et al. (2015), we assume that $50 \%$ of the estimated manufacturing and services NTB costs are cut, which reflects the associated trade cost reductions of moving into a deep preferential trade agreement 26

3. Full TTIP experiment (C): The third scenario combines the two previous scenarios to include both the tariff elimination and the NTB cost reductions.

It is important to note that contrary to the CEPR study (Francois et al., 2013) and the study by Egger et al. (2015), we do not assume that the final regulation cooperation agreements under TTIP will create positive spillovers for third countries. In this context, if the new regulation framework agreed by TTIP becomes the new regulation standard, then these studies assume that third countries will indirectly benefit from a reduction in NTBs, since the new international regulation framework could reduce the associated costs to trade with the EU and the US. However, it is hard to envisage what the end-product of the negotiations on regulation cooperation under TTIP will achieve, and if these sets of new regulations will become the new international regulation norm.

The model is simulated between 2011 and 2030, with all the TTIP shocks scheduled for 2017. The results presented in Table 4 show the long-term effects of TTIP as the difference between the simulated path of the economy and the baseline for 2030 .

From Table 4 we observe that the first scenario with tariff eliminations does not generate much GDP nor consumption per capita gains, with values for the Netherlands being close to zero. In the second scenario with NTB reductions, we do observe significant gains in GDP and consumption, with values of around one percentage point for the EU and the US. The economic gains for the Netherlands are higher than the EU average with a GDP increase of $1.5 \%$ and a $2.8 \%$ increase in consumption. Finally, the full TTIP scenario shows economic gains that are higher than the NTB reduction scenario. In the full TTIP scenario the Netherlands has a $1.7 \%$ GDP increase, which is again higher than the EU average 27

\footnotetext{
${ }^{26}$ This $50 \%$ share is taken from the study by Ecorys (2009), where half of the estimates NTB costs are considered to be "actionable" or possible to reduce, while the other half of these NTB costs are not possible to reduce due to legal, institutional and/or political constraints. See Section 2.1.2 in Bekkers and Rojas-Romagosa (2016) for a detailed description. In addition, following Egger et al. (2015) we also assume that NTBs for financial and insurance services will not be reduced under TTIP.

${ }^{27}$ Note that the full TTIP scenario for the EU28 has lower GDP gains than in the NTBs only scenario. This particular result can be explained by the EU28 being an aggregate of country-specific
} 
Table 4: TTIP simulation results, for each scenario, percentage changes with respect to the baseline in 2030

\begin{tabular}{lrrrrrrrrr}
\hline & \multicolumn{3}{c}{ A. Tariffs only } & \multicolumn{3}{c}{ B. NTBs only } & \multicolumn{3}{c}{ Full (A+B) } \\
& NLD & EU28 & USA & NLD & EU28 & USA & NLD & EU28 & USA \\
& & & & & & & & & \\
GDP & 0.01 & 0.02 & 0.10 & 1.52 & 1.27 & 0.81 & 1.69 & 1.19 & 0.94 \\
consumption per capita & 0.01 & 0.01 & 0.09 & 2.79 & 2.15 & 1.74 & 3.11 & 2.16 & 1.93 \\
export volume & 0.21 & 0.35 & 1.45 & 3.43 & 5.41 & 18.28 & 3.94 & 6.24 & 21.45 \\
import volume & 0.25 & 0.35 & 1.15 & 6.57 & 7.88 & 20.88 & 7.50 & 8.99 & 23.85 \\
real average wage & 0.01 & 0.02 & 0.10 & 2.10 & 1.60 & 1.38 & 2.13 & 1.66 & 1.59 \\
\hline
\end{tabular}

Notes: The scenario A simulates full elimination of bilateral tariffs. Scenario B simulates $50 \%$ cuts in manufacturing and services NTBs, except on Finance and Insurance.

Source: Own WorldScan estimations using GTAP9 database.

The results for the EU and the US are in line with other CGE studies on TTIP, where most of the gains from TTIP are mainly derived from the reduction of NTBs, while the GDP increases are positive and significant for both economic blocs and within the range of one to two percentage point gains. ${ }^{28}$ In addition, we run alternative simulations with different NTB reductions than in the main full TTIP scenario. We find that there is a roughly linear relation between NTB cuts and GDP increases: half the reduction in NTBs, with respect to the full TTIP scenario, is associated with around half the GDP changes. ${ }^{29}$

These GDP gains are directly related to increased trade, reflected in the rise in trade volumes (exports and imports). We also find that the average (i.e. for both high- and low-skill workers) real wages increase significantly in the Netherlands $(2.1 \%)$. In addition, the wage increase is more pronounced for high-skill workers $(2.4 \%)$ than for low-skill workers $(1.8 \%)$, which will generate relatively small rise in wage inequality.

Trade volumes increase mainly due to the significant expansion of bilateral trade between the EU and the US. This is shown in Table 5 where the value of EU exports to the US increase by $111 \%$ and from the US to the EU by $119 \%$. The Netherlands experiences an export increase with the US of 95\%. These significant trade increases between the EU and the US are reflected in higher total exports for both regions, while there is a decrease of trade with third regions 30 In other words, TTIP will

results, with sector-specific trade cost changes, some of which can offset each other and lower the overall results when both tariffs and NTBs are reduced.

${ }^{28}$ When comparing our results with those from Ecorys (2016) we obtain larger GDP effects for the Netherlands. The reason is that Ecorys (2016) follow the estimation technique for NTB costs from Francois et al. (2013), who in general have lower real income effects than the simulations done in Egger et al. (2015), which we follow to estimate NTB costs. See Bekkers and Rojas-Romagosa (2016) for a detailed comparison between the methodologies in Francois et al. (2013) and Egger et al. (2015).

${ }^{25}$ These additional results are presented in Appendix A.2

${ }^{30}$ Note that the total increase in US exports (19.1\%) is much higher than that of the EU (6.2\%) due to the US initial export level being significantly lower than that for the EU. So despite of a relative balanced increase in bilateral exports, the impact on total US exports is then higher. 
generate trade diversion effects. The Netherlands, for instance, increases its total exports by around $4 \%$ but given the strong increase of exports to the US, this comes at the cost of lower exports to other EU countries and to the rest of the World (RoW), which in this table is defined as all the other regions except the US and the EU.

Table 5: Export values in full TTIP scenario, percentage changes with respect to the baseline in 2030

\begin{tabular}{lrrrr}
\hline & Total & to EU & to US & to RoW \\
EU & 6.2 & -3.2 & 111.4 & -0.3 \\
US & 19.1 & 119.0 & 0.0 & -0.3 \\
NLD & 4.3 & -2.0 & 95.4 & -2.8 \\
\hline
\end{tabular}

Note: Percentage changes are for export values, while Table 4 shows changes in export volumes. Source: Own WorldScan estimations using GTAP9 database.

Table 6 presents the sectoral effects for the third scenario (full TTIP) simulations. Here we find that even though overall GDP levels are increasing only by around $1 \%$, there are significant variations in the sectoral output. These divergent sectoral patterns can be explained by initial tariff differentials, but more importantly, because of sector-specific divergence in NTB cost reductions. While some sectors experience significant expansions (e.g. processed foods and most services sectors), other sectors will contract (metals and minerals, and other transport equipment). These output changes are linked to export changes, where in general sectors that are expanding are also exporting more, while contracting sectors are exporting less. The exception is the other transport equipment, that has an output contraction but expands its exports significantly, which means that there is a sharp reorientation of the lower production from the domestic to the foreign market. Moreover, the sectors that are increasing exports are also sectors that were relatively important in total exports, such as: energy, processed foods, chemical, rubber and plastics, and other commercial services.

In general, the shift in relative importance of different sectors generates labour and capital displacement. Sectors that are expanding will attract more workers and investments, while contracting sectors will reduce employment levels. In this context, it is of particular importance that the increased labour demand is reflected in a rise in average wages for both low- and high-skill workers. This result is not surprising given that both the EU and the US have similar high-skilled working populations, and both regions are preponderant in technology-intensive sectors and relatively high-skill levels. 31

Labour displacement, however, will have short term adjustment costs for those workers that need to change employment. These adjustment costs are not accounted

\footnotetext{
${ }^{31}$ If trade was being increased, on the contrary, with a country with relatively more lower-skill workers than the EU -for example with China or India- then the effect on low and high-skill wages will be expected to work differently, with high-skill EU workers benefiting with respect to low-skill workers.
} 
for in the CGE model but are expected to be low. The required labour mobility from TTIP is expected to be well within normal labour market movements (job creation and destruction) in any given year. For instance, in our full TTIP simulation labour reallocation across sectors is estimated to by $1.4 \%$ of the total employed population. With an estimated 8.8 million employed workers in 2014 in the Netherland $\$ 22$ then an estimated 114,000 workers will need to be reallocated to another sector in a 13 year period (between 2017 to 2030). This figure, however, is relatively low compared to the normal job reallocation in the Netherlands, where an estimated $13 \%$ of jobs are created and destroyed in a single year (Brull et al., 2010$)$ - i.e. around one million jobs are reallocated yearly ${ }^{33}$ Part of the low overall employment impact of TTIP is that most of the production and employment changes are concentrated in manufacturing sectors, which account for only around $15 \%$ of total employment. To sum up, relatively few workers would have to change jobs and move from one sector to another.

Finally, the trade diversion effects of TTIP will have an impact on third regions. In Table 7 we show the percentage changes in GDP and exports for non-TTIP regions in our full simulation scenario. We find, however, that these impacts are relatively small. Total export decreases are less than a percentage point for all regions, with even smaller GDP effects. The "other OECD countries" and the "SubSaharan Africa" regions will be the most affected with an overall decrease in exports of around one percentage point and a reduction in GDP of around a quarter of a percentage point.

\section{Additional economic effects from TTIP}

The analyses to estimate the potential economic effects of TTIP, so far, has been focused on what are called the "static" gains from trade. These gains are based on classical comparative advantage theory, where the reduction of trade costs (i.e. tariffs and NTBs) is translated into increased trade for those sectors in which the country has a comparative advantage. These comparative advantages can be explained by relative technological levels and endowments, and by sector-specific differences in efficiency. In this context, the reduction in trade costs from TTIP is associated with a one-off (static) gain that stems from a better reallocation of resources to the most efficient sectors in each economy. This is the basic mechanism behind the CGE model analysis.

\footnotetext{
${ }^{32}$ CBS Open data StatLine website.

${ }^{33}$ It is important to note, however, that this last figure includes mainly within-sector job reallocations, but the case remains that the number of workers that needs to reallocate to another sector is still relatively small in comparison. On the other hand, sectoral job reallocation is also a characteristic feature of the Dutch economy, where in particular, the share of agricultural and manufacturing jobs has been steadily declining over the years, and the share of services jobs has increased. This trend, moreover, is expected to continue in the future (Huizinga and Smid, 2005).
} 
Table 6: Netherlands, sectoral percentage changes in the full TTIP scenario, with respect to the baseline in 2030

\begin{tabular}{|c|c|c|c|c|c|}
\hline \multirow[b]{2}{*}{ Sector } & \multirow[b]{2}{*}{ Code } & \multicolumn{2}{|c|}{ Output } & \multicolumn{2}{|c|}{ Exports } \\
\hline & & 2011 shares & $\%$ change & 2011 shares & $\%$ change \\
\hline Agriculture & AGR & 1.99 & 0.11 & 4.63 & 2.34 \\
\hline Oil and other mining & OMI & 0.20 & -0.01 & 0.18 & 4.70 \\
\hline Energy & ENG & 6.50 & 0.85 & 13.37 & 4.92 \\
\hline Processed foods & $\mathrm{PFO}$ & 5.41 & 5.36 & 11.51 & 10.88 \\
\hline Low-tech manufacturing & LTM & 3.88 & 0.60 & 5.38 & 1.56 \\
\hline Metals and minerals & MEM & 3.90 & -3.26 & 8.23 & -1.88 \\
\hline Chemical, rubber and plastics & $\mathrm{CRP}$ & 4.49 & 4.68 & 17.72 & 7.32 \\
\hline Motor vehicles and parts & MVH & 1.03 & 1.88 & 3.30 & 3.16 \\
\hline Other transport equipment & OTN & 1.00 & -6.68 & 1.25 & 22.68 \\
\hline Electronic equipment & ELE & 1.50 & 0.76 & 2.87 & 1.32 \\
\hline Other machinery and equipment & $\mathrm{OME}$ & 2.79 & 1.31 & 9.07 & 3.17 \\
\hline Construction & OTP & 3.27 & 0.44 & 2.00 & -0.59 \\
\hline Other transport & ATP & 1.11 & 1.05 & 2.29 & 2.21 \\
\hline Air transport & WTP & 1.29 & 1.14 & 0.85 & -0.01 \\
\hline Water transport & CNS & 9.21 & 2.18 & 0.76 & 1.18 \\
\hline Communication & $\mathrm{CMN}$ & 2.39 & 1.22 & 1.37 & 1.39 \\
\hline Finance & OFI & 2.76 & 1.11 & 0.41 & 1.03 \\
\hline Insurance & ISR & 1.46 & 2.20 & 0.46 & 1.18 \\
\hline Other commercial services & OCS & 20.99 & 1.77 & 11.92 & 9.38 \\
\hline Recreational and other services & ROS & 3.73 & 1.49 & 0.72 & 2.46 \\
\hline Government and public services & OSR & 21.09 & 1.71 & 1.72 & 0.57 \\
\hline Total & & 100.00 & 1.69 & 100.00 & 4.34 \\
\hline
\end{tabular}

Table 7: TTIP full scenario, percentage changes with respect to the baseline in 2030

\begin{tabular}{lrrr}
\hline Region & Code & GDP & Exports \\
Other OECD countries & ROE & -0.21 & -0.89 \\
Rest of East Europe & EER & 0.01 & -0.16 \\
China and Hong Kong & CHH & 0.01 & -0.15 \\
ASEAN countries & ASE & -0.05 & -0.26 \\
India & IND & 0.01 & -0.20 \\
Middle East and North Africa & MNA & -0.02 & -0.09 \\
Sub-Saharan Africa & SSA & -0.16 & -0.96 \\
Latin America and the Caribbean & LAC & -0.11 & -0.63 \\
Rest of the World & ROW & 0.02 & -0.27 \\
\hline \multicolumn{2}{c}{ Source: Own WorldScan estimations using GTAP9 database. }
\end{tabular}

Economic theory, however, also predicts that increased trade and exposure to international competition has positive "dynamic" effects on income 34 There are several theoretical mechanisms where trade can increase income growth and pro-

\footnotetext{
${ }^{34}$ These dynamic gains from trade refer to changes in the economy associated with the increase in the growth of income over time.
} 
ductivity: changes in factor accumulation of human and physical capital due to a larger market size (Baldwin, 1992; Wacziarg, 1998), reallocation of resources to firms with higher productivity levels (Melitz, 2003; Bernard et al., 2003), and productivity gains linked to trade-induced innovation 35 There is empirical evidence that firm-level productivity increases due to higher returns to innovation (see Melitz and Trefler, 2012, for an overview). In addition, increased trade flows can also be associated with technological spillovers and learning effects that can indirectly increase innovation and productivity 36

These theoretical dynamic gains from trade, nevertheless, are much harder to estimate empirically. There is a large literature that has estimated the relationship between increased trade (or changes in trade policy) and economic growth (see for example Baldwin, 2002). In general, most studies find a positive relationship, but the magnitude of the effect and the underlying driving factors differ between studies. ${ }^{37}$ More recently, the studies by Feyrer (2009, 2011) find positive and sizeable dynamic gains from trade. For instance, Feyrer (2011) uses the "natural experiment" of the Suez canal closure in 1967 to overcome the methodological limitations in other studies, and finds that trade has a significant impact on income. However, these studies are highly time and event specific, and as such, do not provide reliable estimations on the link between trade flows and productivity or income growth that can be widely used in broad CGE applications. This is the main reason that such "dynamic" mechanisms are usually not included in standard CGE models. Nevertheless, even if it is hard to estimate the dynamic gains from larger Transatlantic trade, it is expected that there will be positive additional dynamic gains from TTIP.

The TTIP negotiations also include public procurement and investment provisions. Correspondingly, TTIP is also expected to increase FDI bilateral flows between both regions. For instance, Francois et al. (2012) also estimate the income gains for MNEs if NTBs associated with investment are lowered as a result of TTIP. Since the US and the EU are the largest recipients of FDI flows between both regions, they find that the simple size of the US market implies large potential gains even if relatively small barriers are removed. Thus, improvements in market access associated with TTIP are likely to imply substantial changes in FDI levels.

Therefore, the potential effects estimated in Section 4.3 are likely to underestimate the full economic effects of TTIP, since our methodology does not analyse

\footnotetext{
${ }^{35}$ In particular, increased innovation and $R \& D$ investments lead to constant improvements over time in productivity and income (Keller, 2002, Bloom et al., 2015). Moreover, there are several links on how increased trade flows can affect innovation levels. For example, more intense competition and higher income prospects from bigger international markets may increase the incentives to innovate, and/or increase the importance of more innovative firms.

${ }^{36} \mathrm{An}$ important indirect effect of innovation is that there are considerable (national and international) spillovers from R\&D investments (e.g. Coe and Helpman, 1995, Coe et al., 2009).

${ }^{37}$ There are also serious data and methodological issues involved. In particular, there are econometric problems with identification (due to the lack of exogenous variation in trade or trade policies) and omitted variables bias. One of the most contentious issues is the identification of trade policy changes, since in many countries broader economic reforms where introduced simultaneously with trade openness measures (Rodríguez and Rodrik, 2001).
} 
additional economic effects from TTIP related to public procurement provisions, increased FDI flows and dynamic gains from trade.

Finally, the Netherlands is a relatively small and open economy, and the importance of international trade is higher than for economies that are larger and rely less on trade (i.e. the US). Under these circumstances, any change in trade flows and their associated economic (static and dynamic) gains have a larger impact than for other countries. This is reflected on the higher potential gains that the Netherlands will have from TTIP with respect to other EU countries.

\section{Conclusions}

TTIP is an ambitious and comprehensive preferential trade agreement that is expected to have a significant effect in EU and US trade and investment relations. Following several studies and our own CGE simulations, it is predicted that bilateral trade between both regions will roughly double. For the Netherlands, this is translated into a positive but moderate effect on income of $1.7 \%$ by the year 2030 . These potential gains are higher than those for the EU and the US (both around $1 \%$ ). Moreover, there are potential average real wage gains of more than $2 \%$, while the associated labour movement between contracting and expanding sectors is expected to be within yearly labour market mobility flows. Increased transatlantic trade will also generate trade diversion effects, where bilateral trade between the US and the EU increases, while intra-EU trade and trade with third countries decreases. However, the overall export and income effects on these third countries will be relatively small, with export decreases well below one percentage point and with potential GDP reductions close to zero.

These expected results, nevertheless, are conditional on the final negotiated agreement. Most CGE studies use as benchmark an "ambitious" deal that will significantly reduce current NTB levels, which are the most important remaining trade costs in transatlantic integration. Given the lack of concrete intermediate negotiated outcomes, this is the best approach that can be taken for now. On the other hand, the potential economic effects are only a tentative estimation of the impact of TTIP, and a more detailed economic analysis should be done once the final outcome of the negotiations is known.

\section{References}

Baetens, F. (2015). "Transatlantic Investment Treaty Protection - A Response to Poulsen, Bonnitcha and Yackee," in Rule-Makers or Rule-Takers? Exploring the Transatlantic Trade and Investment Partnership, ed. by D. S. Hamilton and J. Pelkmans, Centre for European Policy Studies (CEPS) and Center for Transatlantic Relations (CTR).

Baldwin, R. (1992). "Measurable Dynamic Gains from Trade," Journal of Political Economy, 100(1): 162-174. 
Baldwin, R. E. (2002). "Openness and Growth: What's the Empirical Relationship?" in Challenges to Globalization: Analyzing the Economics, ed. by R. E. Baldwin and L. A. Winters, University of Chicago Press.

Bekkers, E. and H. Rojas-Romagosa (2016). "Literature survey on the economic impact of TTIP," CPB Background Document, CPB Netherlands Bureau for Economic Policy.

Berden, K. and J. Francois (2015). "Quantifying Non-Tariff Measures for TTIP," in Rule-Makers or Rule-Takers? Exploring the Transatlantic Trade and Investment Partnership, ed. by D. S. Hamilton and J. Pelkmans, Centre for European Policy Studies (CEPS) and Center for Transatlantic Relations (CTR).

Bernard, A. B., J. Eaton, J. B. Jensen, and S. Kortum (2003). "Plants and Productivity in International Trade," American Economic Review, 93(4): 1268-1290.

Bloom, N., M. Draca, and J. Van Reenen (2015). "Trade Induced Technical Change?" Review of Economic Studies, 83(4): 87-117.

Brull, A., F. A. den Butter, and P. Kee (2010). "The Definition of a Job and the Flow Approach to the Labour Market: A Sensitivity Analysis for the Netherlands," Discussion Paper 10011, Statistics Netherlands (CBS).

Chase, P. and J. Pelkmans (2015). "This Time It's Different: Turbo-Charging Regulatory Cooperation," in Rule-Makers or Rule-Takers? Exploring the Transatlantic Trade and Investment Partnership, ed. by D. S. Hamilton and J. Pelkmans, Centre for European Policy Studies (CEPS) and Center for Transatlantic Relations (CTR).

Coe, D. and E. Helpman (1995). "International R\&D Spillovers," European Economic Review, 39(5): 859-887.

Coe, D., E. Helpman, and A. Hoffmaister (2009). "International R\&D Spillovers and Institutions," European Economic Review, 53(7): 723-741.

de Bruijn, R. (2006). "Scale Economies and Imperfect Competition in WorldScan," CPB Memorandum 140, CPB Netherlands Bureau for Economic Policy Analysis.

Ecorys (2009). "Non-Tariff Measures in EU-US Trade and Investment: An Economic Analysis," Report prepared by Koen G. Berden, Joseph F. Francois, Saara Tamminen, Martin Thelle, and Paul Wymenga for the European Commission, Reference OJ 2007/S180-219493, ECORYS Nederland BV.

Ecorys (2012). "Study on EU-US High Level Working Group," Final Report for the Dutch Ministry of Economic Affairs, Agriculture and Innovation.

Ecorys (2016). "Trade SIA on the Transatlantic Trade and Investment Partnership (TTIP) between the EU and the USA," Draft Interim Technical Report, European Commission, Directorate-General for Trade. 
Egan, M. and J. Pelkmans (2015). "TTIP's Hard Core; Technical Barriers to Trade and Standards," in Rule-Makers or Rule-Takers? Exploring the Transatlantic Trade and Investment Partnership, ed. by D. S. Hamilton and J. Pelkmans, Centre for European Policy Studies (CEPS) and Center for Transatlantic Relations (CTR).

Egger, P., J. Francois, M. Manchin, and D. Nelson (2015). "Non-tariff Barriers, Integration, and the Transatlantic Economy," Economic Policy, 30(83): 539-584.

Egger, P. and M. Larch (2011). "An Assessment of the Europe Agreements' Effects on Bilateral Trade, GDP, and Welfare," European Economic Review, 55(2): 263279 .

European Commission (2013). "Transatlantic Trade and Investment Partnership: The Economic Analysis Explained," Technical Report, European Commission.

Feyrer, J. (2009). "Trade and Income: Exploiting Time Series in Geography," NBER Working Paper 14910.

Feyrer, J. (2011). "Distance, Trade, and Income: The 1967 to 1975 Closing of the Suez Canal as a Natural Experiment," NBER Working Paper 15557.

Fontagné, L., J. Gourdon, and S. Jean (2013). "Transatlantic Trade: Whither Partnership, which Economic Consequences?" CEPII Policy Brief No. 1, CEPII.

Francois, J., M. Manchin, H. Norberg, O. Pindyuk, and P. Tomberger (2013). "Reducing Transatlantic Barriers to Trade and Investment: An Economic Assessment," Final Project Report, prepared under implementing Framework Contract TRADE10/A2/A16, CEPR, London.

Francois, J. F., M. Manchin, and W. Martin (2012). "Market Structure in CGE Models of International Trade," in Handbook of Computable General Equilibrium Modeling, ed. by P. Dixon and D. Jorgenson, Amsterdam: Elsevier.

Francois, J. F. and D. Nelson (2002). "A Geometry of Specialization," Economic Journal, 112(481): 649-678.

Francois, J. F. and D. Roland-Holst (1997). "Scale Economies and Imperfect Competition," in Applied Methods for Trade Policy Analysis: A Handbook, ed. by J. F. Francois and K. A. Reinert, Cambridge: Cambridge University Press, 331-362.

Hamilton, D. S. and J. Pelkmans (2015). "Rule-Makers or Rule-Takers? An Introduction to TTIP," in Rule-Makers or Rule-Takers? Exploring the Transatlantic Trade and Investment Partnership, ed. by D. S. Hamilton and J. Pelkmans, Centre for European Policy Studies (CEPS) and Center for Transatlantic Relations (CTR). 
Hertel, T. (2013). "Global Applied General Equilibrium Analysis Using the Global Trade Analysis Project Framework," in Handbook of Computable General Equilibrium Modeling, ed. by P. Dixon and D. Jorgenson, Amsterdam: Elsevier.

Huizinga, F. and B. Smid (2005). "Four Futures of the Netherlands: Production, Labour and Sectoral Structure in Four Scenarios until 2040," CPB Memorandum April 15th, CPB Netherlands Bureau for Economic Policy Analysis.

Jafari, Y. and D. G. Tarr (2015). "Estimates of Ad Valorem Equivalents of Barriers Against Foreign Suppliers of Services in Eleven Services Sectors and 103 Countries," World Economy, doi: 10.1111/twec.12329.

Keller, W. (2002). "Trade and the Transmission of Technology," Journal of Economic Growth, 7(1): 5-24.

Lane, P. and G. Milesi-Ferreti (2001). "Long-Term Capital Movements," NBER Working Paper 8366.

Lejour, A. M., P. Veenendaal, G. Verweij, and N. van Leeuwen (2006). "WorldScan: A Model for International Economic Policy Analysis," CPB Document 111.

Melitz, M. (2003). "The Impact of Trade on Intra-Industry Reallocations and Aggregate Industry Productivity," Econometrica, 71(6): 1695-725.

Melitz, M. and D. Trefler (2012). "Gains from Trade When Firms Matter," Journal of Economic Perspectives, 26(2): 91-118.

Mustilli, F. (2015). "Estimating the Economic Gains of TTIP," Intereconomics, 50(6): $321-327$.

Narayanan, B. G., A. Aguiar, and R. McDougal, eds. (2015). Global Trade, Assistance, and Production: The GTAP 9 Data Base, Center for Global Trade Analysis: Purdue University.

Pelkmans, J., A. Lejour, L. Schrefler, F. Mustilli, and J. Timini (2014). "EU-US Transatlantic Trade and Investment Partnership: Detailed Appraisal of the European Commission's Impact Assessment," Ex-Ante Impact Assessment Unit Study, European Parliamentary Research Service, European Parliament.

Poulsen, L., J. Bonnitcha, and J. Yackee (2015). "Transatlantic Investment Treaty Protection," in Rule-Makers or Rule-Takers? Exploring the Transatlantic Trade and Investment Partnership, ed. by D. S. Hamilton and J. Pelkmans, Centre for European Policy Studies (CEPS) and Center for Transatlantic Relations (CTR).

Rodríguez, F. and D. Rodrik (2001). "Trade Policy and Economic Growth: A Skeptic's Guide to the Cross-NationalEvidence," in Macroeconomics Annual 2000, ed. by B. Bernanke and K. Rogoff, Cambridge, USA: MIT Press. 
Rodrik, D. (2015). "The War of Trade Models," Dani Rodrik's weblog (rodrik.typepad.com), May 4th.

Rutherford, T. F. and S. V. Paltsev (2000). "GTAPinGAMS and GTAP-EG: Global Datasets for Economic Research and Illustrative Models," Working paper, University of Colorado, Boulder.

SER (2016). "Key Points of SER's Advisory Report on TTIP," Advies TTIP, Social and Economic Council of the Netherlands (SER).

The Economist (2013). "Transatlantic Trade Talks: Opening Shots," July 6th, Print Edition.

The Guardian (2015). "What is TTIP? The Controversial Trade Deal Proposal Explained," July 3rd, Print Edition.

UN (2015). "World Population Prospects: The 2015 Revision, Methodology of the United Nations Population Estimates and Projections." Tech. rep., United Nations, Department of Economic and Social Affairs, Population Division.

Wacziarg, R. (1998). "Measuring the Dynamic Gains from Trade," Policy Research Working Paper Series 2001, World Bank.

Wolf, M. (2015). "The Embattled Future of Global Trade Policy," May 12th, The Financial Times. 


\section{A Appendix}

\section{A.1 Technical specifications of the WorldScan CGE model}

A computational general equilibrium (CGE) model consists of three main elements. The underlying general equilibrium economic model, the multi-regional input-output data and a set of exogenous parameters (being the most import the elasticities). The combination of these three elements yields a general equilibrium (calibrated) baseline in which all the accounting and market clearing conditions are met. Policy experiments consist of a shock to one or several exogenous variable (e.g. tariffs) that generate changes in the price and quantities of the endogenous variables such that a new general equilibrium is reached: the counterfactual scenario. The behavioural equations in the economic model determine how the endogenous variables react, while the underlying baseline data and the exogenous parameters (i.e. the various elasticities in the model) determine the size and scope of the adjustments.

\section{Economic model}

General equilibrium models describe supply and demand relations in markets. In these models, prices and quantities of goods and factor inputs (i.e. labour and capital) adjust, such that demand and supply become equal at an equilibrium price and quantity level. These models also describe the interactions between several markets. For instance, firms must determine the factor inputs necessary to produce a final good, given the price and demand of that good. Firms' supply decisions, therefore, depend on the equilibrium product price and in turn they determine the demand for the necessary intermediate and factor inputs required. Consumers preferences and budget constrains will determine the demand for final goods and the supply of factor inputs (mainly labor). The interaction of the optimisation decisions by firms and consumers will ultimately determine the equilibrium prices and quantities of goods and factor inputs.

Therefore, the core elements of all CGE models are the micro-economic founded neo-classical conditions: consumer and producer optimisation under budgetary constraints. Hence, economic behaviour drives the adjustment of quantities and prices given that consumers maximise utility given the price of goods and the consumers' budget constraints, while producers minimise costs, given input prices, the level of output and production technology.

These optimisation conditions are linked with market clearing conditions in the products markets (i.e. equating demand and supply for each production sector). The number of product markets is defined by the number of economic sectors in the database. For instance, the GTAP database identifies 57 sectors. Ina addition there are also market clearing conditions for the factor markets. Following the example above, the supply of low- and high-skill labour by households must equal the demand of these factor inputs by firms. There are five different factor types 
in GTAP: unskilled and skilled labour, capital, land and natural resources 38 For instance, the demand of labour (determined from the profit maximisation conditions of firms) must equal the labour supply by households (which in turn is a function of economically active population and labour participation rates.)

Consumption is modelled as non-homothetic demand system using the linear expenditure system (LES). All partial elasticities of substitution for composite commodities as well as price and income elasticities drive demand responses to economic shocks. Production is modelled as a nested structure of constant elasticities of substitution (CES) functions. The values of the substitution parameters reflect the substitution possibilities between intermediate inputs and production factors.

We employ the WorldScan version with monopolistic competition and increasing returns to scale (de Bruijn, 2006). This version of the model is based on a Dixit-Stiglitz-Armington demand specification. In particular, it uses the love-ofvariety -i.e. Dixit-Stiglitz (DS)- preferences for intermediate and final goods for non-agricultural sectors. Within a representative firm, individual varieties are symmetrical in terms of selling at the same price and quantity, but that increases in the number of varieties yield economic benefits because they are perceived to be different by intermediate and final demand agents. This DS approach is then nested within a basic CES demand system that includes both Armington- and DS-type demand systems for individual sectors using Ethier and Krugman-type monopolistic competition models -i.e. differentiated intermediate and differentiated consumer goods. ${ }^{39}$

This DS-Armington structure is combined with a monopolistic competition setting with economies of scale. While firms behave as monopolists, the existence of free entry drives economic profits to zero, so that pricing is at average cost, as is the case in the perfect competition specification. Economies of scale are then modelled using the concept of variety-scaled goods. We can define 'variety-scaled output', which refers to physical quantities, with a 'scaling' or quality coefficient that reflects the varieties embodied on total physical output. This variety-scaled output can be substituted directly into an Armington-type demand system. The precise modelling in the CGE-GTAP code is done by means of a closure swap that yields output level and variety scaling effects at the sectoral level. This implies that sectoral productivity is now endogenous in the model and it adjusts to capture the output scale and variety effects.

Finally, the model provides an explicit and detailed treatment of international trade, international transport margins and other trade costs (e.g. tariffs, NTBs, export subsidies). Bilateral trade is handled via CES (constant elasticity of substitution) preferences for intermediate and final goods, using the so-called Armington assumption, where the substitution of domestics and imports -as well as product

\footnotetext{
${ }^{38}$ The most recent GTAP-9 version identifies five different labour types, but these can be aggregated to the common two labour types used in most CGE models.

${ }^{39}$ This can be done because one can reduce Ethier-Krugman-models algebraically to Armingtontype demand systems with external scale economies linked to a variety of effects (Francois and Roland-Holst, 1997, Francois and Nelson, 2002).
} 
differentiation - is driven by the region of origin (i.e. by import source). This assumption is generic to most CGE models as it is a simple device to account for "cross-hauling" of trade (i.e. the empirical observation that countries often simultaneously import and export goods in the same product category).

A summary of the general equilibrium equations of WorldScan is provided in Appendix A in Lejour et al. (2006)

\section{Underlying data and calibration}

The primary data input is a global multi-regional input-output (GMRIO) database. In particular, we use the GTAP database, which provides balanced and harmonised input-output matrices, bilateral trade and protection data. For this particular WorldScan simulation we use GTAP-9 database with base-year 2011 (cf. Narayanan et al. 2015). The specific sectoral and regional aggregation is presented in Tables 8 and 9 , respectively.

Table 8: Sectoral GTAP aggregation used in WorldScan simulations

\begin{tabular}{|c|c|c|c|c|}
\hline number & code & WorldScan sector & Aggregated GTAP Sectors & GTAP codes \\
\hline 1 & AGR & Agriculture & $\begin{array}{l}\text { Paddy rice, Wheat, Other cereal grains, Vegetables \& fruits, } \\
\text { Oil seeds, Sugar cane, Plant-based fibers, Other crops, } \\
\text { Bovine cattle, Other animal products, Raw milk, Wool, } \\
\text { Forestry, Fishing }\end{array}$ & $\begin{array}{l}\text { PDR, WHT, GRO, V_F, } \\
\text { OSD, C_B, PFB, OCR, } \\
\text { CTL, OAP, RMK, WOL, } \\
\text { FRS, FSH }\end{array}$ \\
\hline 2 & OMI & Oil and other mining & Oil, Other minerals & OIL, OMN \\
\hline 3 & ENG & Energy & $\begin{array}{l}\text { Coal, Natural gas, Petroleum \& coal products } \\
\text { Electricity, Gas manufacture \& distribution }\end{array}$ & $\begin{array}{l}\text { COA, GAS, P_C } \\
\text { ELY, GDT }\end{array}$ \\
\hline 4 & $\mathrm{PFO}$ & Processed foods & $\begin{array}{l}\text { Bovine meat products, Other meat products, Vegetable oils } \\
\text { Dairy products, Processed rice, Sugar, Other food products } \\
\text { Beverages \& tobacco }\end{array}$ & $\begin{array}{l}\text { CMT, OMT, VOL, } \\
\text { MIL, PCR, SGR, OFD, } \\
\text { B_T }\end{array}$ \\
\hline 5 & LTM & Low-tech manufacturing & $\begin{array}{l}\text { Textiles, Wearing apparel, Leather products, Wood products } \\
\text { Paper products \& publishing, Other manufactures }\end{array}$ & $\begin{array}{l}\text { TEX, WAP, LEA, LUM, } \\
\text { PPP, OMF }\end{array}$ \\
\hline 6 & MEM & Metals and minerals & $\begin{array}{l}\text { Other mineral products, Ferrous metals, Other metals } \\
\text { Metal products }\end{array}$ & $\begin{array}{l}\text { NMM, I_S, NFM, } \\
\text { FMP }\end{array}$ \\
\hline 7 & $\mathrm{CRP}$ & Chemical, rubber and plastics & Chemical, rubber \& plastic products & CRP \\
\hline 8 & MVH & Motor vehicles and parts & Motor vehicles \& parts & MVH \\
\hline 9 & OTN & Other transport equipment & Other transport equipment & OTN \\
\hline 10 & ELE & Electronic equipment & Electronic equipment & ELE \\
\hline 11 & OME & Other machinery and equipment & Other machinery \& equipment & OME \\
\hline 12 & CNS & Construction & Construction & CNS \\
\hline 13 & WTP & Water transport & Water transport & WTP \\
\hline 14 & ATP & Air transport & Air transport & ATP \\
\hline 15 & OTP & Other transport & Other Transport & OTP \\
\hline 16 & $\mathrm{CMN}$ & Communication & Communication & $\mathrm{CMN}$ \\
\hline 17 & OFI & Finance & Other financial services & OFI \\
\hline 18 & ISR & Insurance & Insurance & ISR \\
\hline 19 & OCS & Other commercial services & Trade, Other business services & TRD, OBS \\
\hline 20 & ROS & Recreational and other services & Recreational \& other services & ROS \\
\hline 21 & OSR & Government and public services & Water, Public administration \& public services, Dwellings & WTR, OSG, DWE \\
\hline
\end{tabular}

The economic model is then calibrated to the GTAP base year of 2011 using a set of exogenous parameters (mainly consumption and production elasticities). Our baseline scenario runs from 2011 to 2030 . To construct this scenario we combine the GTAP9 data with the following additional data:

- GDP growth per capita projections taken from the OECD. 
Table 9: Regional GTAP aggregation used in WorldScan simulations

\begin{tabular}{cll}
\hline Number & Code & Country/Region description \\
1 & AUT & Austria \\
2 & BAL & Baltic countries \\
3 & BGR & Bulgaria \\
4 & BLU & Belgium and Luxembourg \\
5 & CCM & Croatia, Cyprus and Malta \\
6 & CZE & Czech Republic \\
7 & DNK & Denmark \\
8 & FIN & Finland \\
9 & FRA & France \\
10 & DEU & Germany \\
11 & GRC & Greece \\
12 & HUN & Hungary \\
13 & IRL & Ireland \\
14 & ITA & Italy \\
15 & NLD & Netherlands \\
16 & POL & Poland \\
17 & PRT & Portugal \\
18 & ROU & Romania \\
19 & SVK & Slovakia \\
20 & SVN & Slovenia \\
21 & ESP & Spain \\
22 & SWE & Sweden \\
23 & GBR & United Kingdom \\
24 & USA & United States \\
25 & ROE & Rest of OECD \\
26 & EER & Rest of East Europe \\
27 & CHH & China and Hong Kong \\
28 & ASE & ASEAN \\
29 & IND & India \\
30 & MNA & Middle East and North Africa \\
31 & SSA & Sub-Saharan Africa \\
32 & LAC & Latin America and the Caribbean \\
33 & ROW & Rest of the World \\
\hline & & \\
& &
\end{tabular}

- Total labour supply (LSup) is built using a combination of demographic and labour data projections, as:

$$
L S u p_{t}=\operatorname{Pop}_{t} * P R_{t} *\left(1-\mu_{t}\right)
$$

where $\mathrm{Pop}_{t}$ is total population in year $t$ with projections taken from the Medium Variant of projections by the United Nations (UN, 2015) (for nonEU countries) and EuroStat population projections for EU countries. Labour participation rates (PR) are taken from ILO projections. ${ }^{40}$ Long-term unemployment rates $(\mu)$ are taken from from EuroStat and World Bank projections.

- Trade balances are projected to gradually decrease over time. As an initial benchmark we use the updated 2011 net foreign assets data from Lane and Milesi-Ferreti (2001).

\footnotetext{
${ }^{40}$ From the Economically Active Population Estimates and Projections (EAPEP).
} 
The initial (calibrated) condition of the model is that supply and demand are in balance at some equilibrium set of prices and quantities; where workers are satisfied with their wages and employment, consumers are satisfied with their basket of goods, producers are satisfied with their input and output quantities and savings are fully expended on investments. Adjustment to a new equilibrium, governed by behavioural equations and parameters in the model, are largely driven by price linkage equations that determine economic activity in each product and factor market. For any perturbation to the initial equilibrium, all endogenous variables (i.e. prices and quantities) adjust simultaneously until the economy reaches a new equilibrium. Constraints on the adjustment to a new equilibrium include a suit of accounting relationships that dictate that in aggregate, the supply of goods equals the demand for goods, total exports equals total imports, all (available) workers and capital stock is employed, and global savings equals global investment; unless adjustments to these assumptions are modified for a particular application.

\section{A.2 TTIP simulations with different NTB reductions}

Table 10 presents the main macroeconomic results of TTIP with different NTB reductions than those presented in the main scenario (Table 4). We observe that there is a quasi-linear relation between NTB cuts and GDP gains: i.e. reducing the NTB reductions by half, also reduced the GDP gains by roughly half.

Table 10: TTIP simulation results using different NTB reductions, percentage changes with respect to the baseline in 2030

\begin{tabular}{lrrrrrrrrr}
\hline & \multicolumn{3}{c}{ Full TTIP } & \multicolumn{3}{c}{$\mathbf{5 0 \%}$ NTB reduction } & \multicolumn{3}{c}{ 25\% NTB reduction } \\
& NLD & EU28 & USA & NLD & EU28 & USA & NLD & EU28 & USA \\
& & & & & & & & & \\
GDP & 1.69 & 1.19 & 0.94 & 0.81 & 0.59 & 0.55 & 0.39 & 0.30 & 0.33 \\
consumption per capita & 3.11 & 2.16 & 1.93 & 1.33 & 0.89 & 0.86 & 0.61 & 0.41 & 0.44 \\
export volume & 3.94 & 6.24 & 21.45 & 1.80 & 2.81 & 9.95 & 0.94 & 1.47 & 5.33 \\
import volume & 7.50 & 8.99 & 23.85 & 3.11 & 3.70 & 10.16 & 1.51 & 1.82 & 5.12 \\
real average wage & 2.13 & 1.66 & 1.59 & 0.91 & 0.68 & 0.73 & 0.42 & 0.32 & 0.39 \\
\hline
\end{tabular}

Notes: The 50 and $25 \%$ NTB reduction are relative to the NTB reductions in the full TTIP scenario.

Source: Own WorldScan estimations using GTAP9 database. 
Publisher:

\section{CPB Netherlands Bureau for Economic Policy Analysis}

P.O. Box $80510 \mid 2508 \mathrm{GM}$ The Hague

$\mathrm{T}(070) 3383380$

July 2016 | ISBN 978-90-5833-738-2 